\title{
Technical Note: On the Matt-Shuttleworth approach to estimate crop water requirements
}

\author{
J. P. Lhomme ${ }^{1}$, N. Boudhina ${ }^{1,2}$, and M. M. Masmoudi ${ }^{2}$ \\ ${ }^{1}$ Institut de Recherche pour le Développement (IRD) - UMR LISAH, 2 Place Viala, 34060 Montpellier, France \\ ${ }^{2}$ Institut National Agronomique de Tunisie (INAT), 43 Avenue Charles Nicolle, 1082 Tunis, Tunisia
}

Correspondence to: J. P. Lhomme (jean-paul.lhomme@ird.fr)

Received: 10 March 2014 - Published in Hydrol. Earth Syst. Sci. Discuss.: 14 April 2014

Revised: 19 August 2014 - Accepted: 25 September 2014 - Published: 4 November 2014

\begin{abstract}
The Matt-Shuttleworth method provides a way to make a one-step estimate of crop water requirements with the Penman-Monteith equation by translating the crop coefficients, commonly available in United Nations Food and Agriculture Organization (FAO) publications, into equivalent surface resistances. The methodology is based upon the theoretical relationship linking crop surface resistance to a crop coefficient and involves the simplifying assumption that the reference crop evapotranspiration $\left(\mathrm{ET}_{0}\right)$ is equal to the Priestley-Taylor estimate with a fixed coefficient of 1.26. This assumption, used to eliminate the dependence of surface resistance on certain weather variables, is questionable; numerical simulations show that it can lead to substantial differences between the true value of surface resistance and its estimate. Consequently, the basic relationship between surface resistance and crop coefficient, without any assumption, appears to be more appropriate for inferring crop surface resistance, despite the interference of weather variables.
\end{abstract}

\section{Introduction}

The most common way of estimating crop water requirements, as recommended by the United Nations Food and Agriculture Organization (FAO) (Doorenbos and Pruitt, 1977; Allen et al., 1998), consists of the so-called "two-step" approach: firstly, a reference crop evapotranspiration $\left(\mathrm{ET}_{0}\right)$, defined under optimal conditions, is calculated from weather data measured at a reference height; secondly, evapotranspiration from any other well-watered crop $\left(\mathrm{ET}_{\mathrm{c}}\right)$ is obtained by multiplying the reference evapotranspiration by an empirical crop coefficient: $K_{\mathrm{c}}$. The basic relationship writes

$\mathrm{ET}_{\mathrm{c}}=K_{\mathrm{c}} \mathrm{ET}_{0}$.
The effect of weather conditions is supposed to be incorporated into $\mathrm{ET}_{0}$, and the crop characteristics into $K_{\mathrm{c}}$. The estimated values of crop coefficients exist in tabulated form and can be found in many FAO publications. Although the methods used to define and calculate $\mathrm{ET}_{0}$ have changed over the years (Shuttleworth, 1993), FAO-56 (Allen et al., 1998) presently defines $\mathrm{ET}_{0}$ as the daily evapotranspiration from "a hypothetical reference crop with an assumed crop height of $0.12 \mathrm{~m}$, a fixed surface resistance $r_{\mathrm{s}, 0}=70 \mathrm{~s} \mathrm{~m}^{-1}$ and an albedo of 0.23 ", calculated by means of the PenmanMonteith equation (Monteith, 1965):

$\mathrm{ET}_{0}=\frac{\Delta A_{0}+\rho c_{\mathrm{p}} D_{r} / r_{\mathrm{a}, 0}}{\Delta+\gamma\left(1+\frac{r_{\mathrm{s}, 0}}{r_{\mathrm{a}, 0}}\right)}$

$A_{0}=R_{\mathrm{n}, 0}-G_{0}$ is the available energy of the reference crop ( $R_{\mathrm{n}, 0}$ : net radiation; $G_{0}$ : soil heat flux); $D_{\mathrm{r}}$ is the water vapour pressure deficit at a reference height $z_{\mathrm{r}}=2 \mathrm{~m}$ (screen height for weather data measurements); $r_{\mathrm{a}, 0}$ is the aerodynamic resistance calculated between the mean canopy source height and the reference height; the other parameters are defined in the nomenclature. It is specified that "the reference surface closely resembles an extensive surface of green grass of uniform height, actively growing, completely shading the ground and with adequate water". The "one-step" approach, as opposed to the two-step approach, consists of estimating crop evapotranspiration directly from a PenmanMonteith equation similar to Eq. (2), with the effective surface resistance of the crop used in replacement of the crop coefficient. Two main problems arise, however, in using the one-step method. Firstly, when several crops have a crop height close to (or greater than) the reference height of $2 \mathrm{~m}$, a means should be designed to infer weather variables at a higher level than the reference height to be introduced in the 
Penman-Monteith equation. Secondly, the surface resistance is generally unknown for most of the crops and should be determined, either experimentally or by calculation.

The Matt-Shuttleworth (M-S) approach (Shuttleworth, 2006, 2012) provides a response to both questions: it infers weather variables at a blending height higher than the screen height and it calculates crop surface resistance from the FAO crop coefficient. These two steps are first summarized, stressing that the way in which the $\mathrm{M}-\mathrm{S}$ approach infers crop surface resistance relies on a questionable assumption concerning the estimation of $\mathrm{ET}_{0}$. Numerical simulations are carried out to prove that this assumption can be partially misleading. As a consequence, some conclusions are drawn on the applicability and reliability of the Matt-Shuttleworth one-step method.

\section{Inferring weather variables at a higher level}

In the Matt-Shuttleworth approach, the evapotranspiration from a given crop under standard conditions (i.e. unstressed vegetation, as defined in FAO-56), is expressed in the form of a Penman-Monteith equation, but with air characteristics taken at a blending height arbitrarily set at $z_{\mathrm{b}}=50 \mathrm{~m}$ (Shuttleworth, 2006, 2007):

$\mathrm{ET}_{\mathrm{c}}=\frac{\Delta A_{\mathrm{c}}+\rho c_{\mathrm{p}} D_{\mathrm{b}} / r_{\mathrm{a}, \mathrm{c}}}{\Delta+\gamma\left(1+\frac{r_{\mathrm{s}, \mathrm{c}}}{r_{\mathrm{a}, \mathrm{c}}}\right)}$.

$A_{\mathrm{c}}$ is the available energy of the crop and $r_{\mathrm{s}, \mathrm{c}}$ is the crop surface resistance, which is unknown and should be determined. $D_{\mathrm{b}}$ is the water vapour pressure deficit at the blending height obtained by expressing $\mathrm{ET}_{0}$ in two different forms, with weather variables taken respectively at blending height $z_{\mathrm{b}}(=50 \mathrm{~m})$ and reference height $z_{\mathrm{r}}(=2 \mathrm{~m})$, and by assuming that there is no significant divergence of mass and energy fluxes between the reference height and the blending height (Shuttleworth, 2006):

$$
\frac{\Delta A_{0}+\rho c_{\mathrm{p}} D_{\mathrm{b}} / r_{\mathrm{a}, 0, \mathrm{~b}}}{\Delta+\gamma\left(1+\frac{r_{\mathrm{s}, 0}}{r_{\mathrm{a}, 0, \mathrm{~b}}}\right)}=\frac{\Delta A_{0}+\rho c_{\mathrm{p}} D_{\mathrm{r}} / r_{\mathrm{a}, 0}}{\Delta+\gamma\left(1+\frac{r_{\mathrm{s}, 0}}{r_{\mathrm{a}, 0}}\right)} .
$$

The resistance $r_{\mathrm{a}, 0, \mathrm{~b}}$ is the aerodynamic resistance between the reference crop and the blending height and $\Delta$ is calculated at the reference temperature $T_{\mathrm{r}}$. Some mathematical manipulations of Eq. (4) lead to

$$
\begin{aligned}
D_{\mathrm{b}} & =\left(D_{\mathrm{r}}+\frac{\Delta A_{0} r_{\mathrm{a}, 0}}{\rho c_{\mathrm{p}}}\right)\left[\frac{(\Delta+\gamma) r_{\mathrm{a}, 0, \mathrm{~b}}+\gamma r_{\mathrm{s}, 0}}{(\Delta+\gamma) r_{\mathrm{a}, 0}+\gamma r_{\mathrm{s}, 0}}\right] \\
& -\frac{\Delta A_{0} r_{\mathrm{a}, 0, \mathrm{~b}}}{\rho c_{\mathrm{p}}}
\end{aligned}
$$

The crop aerodynamic resistance $r_{\mathrm{a}, \mathrm{c}}$ (see Eq. 16) is calculated from the wind speed at blending height $\left(u_{\mathrm{b}}\right)$, which is inferred from the one measured at reference height $\left(u_{\mathrm{r}}\right)$, assuming there is no divergence of momentum flux between these two heights: $u_{\mathrm{b}}=u_{\mathrm{r}} \frac{\ln \left(\frac{z_{\mathrm{b}}-d_{0}}{z_{\mathrm{om}, 0}}\right)}{\ln \left(\frac{z_{\mathrm{r}}-d_{0}}{z_{\mathrm{om}, 0}}\right)}$,

where $d_{0}$ is the zero plane displacement height of the reference crop and $z_{0 \mathrm{~m}, 0}$ its roughness length for momentum.

\section{Inferring crop surface resistance from the FAO crop coefficient}

The evapotranspiration from any given crop $\mathrm{ET}_{\mathrm{c}}$ (Eq. 3) can be expressed as a function of the reference evapotranspiration $\mathrm{ET}_{0}$ (Eq. 2) in the following way (Pereira et al., 1999, Eq. 25; Shuttleworth, 2006, Eq. 10):

$\mathrm{ET}_{\mathrm{c}}=\alpha_{\mathrm{a}} \alpha_{\mathrm{s}} \mathrm{ET}_{0}$,

where the coefficients $\alpha_{\mathrm{a}}$ and $\alpha_{\mathrm{s}}$ are given by

$\alpha_{\mathrm{a}}=\frac{\Delta f_{\mathrm{c}} A_{0} r_{\mathrm{a}, \mathrm{c}}+\rho c_{\mathrm{p}} D_{\mathrm{b}}}{\Delta A_{0} r_{\mathrm{a}, 0}+\rho c_{\mathrm{p}} D_{\mathrm{r}}}$
$\alpha_{\mathrm{s}}=\frac{(1+\Delta / \gamma) r_{\mathrm{a}, 0}+r_{\mathrm{s}, 0}}{(1+\Delta / \gamma) r_{\mathrm{a}, \mathrm{c}}+r_{\mathrm{s}, \mathrm{c}}}$.

The parameter $f_{\mathrm{c}}=A_{\mathrm{c}} / A_{0}$ allows for differences in available energy between the crop $\left(A_{\mathrm{c}}\right)$ and the reference crop $\left(A_{0}\right)$. Comparing Eq. (7) with Eq. (1) leads to $K_{\mathrm{c}}=\alpha_{\mathrm{a}} \alpha_{\mathrm{s}}$, from which the crop surface resistance can be inferred:

$r_{\mathrm{s}, \mathrm{c}}=\frac{\alpha_{\mathrm{a}}}{K_{\mathrm{c}}}\left[\left(1+\frac{\Delta}{\gamma}\right) r_{\mathrm{a}, 0}+r_{\mathrm{s}, 0}\right]-\left(1+\frac{\Delta}{\gamma}\right) r_{\mathrm{a}, \mathrm{c}}$.

The coefficient $\alpha_{\mathrm{a}}$ can be rewritten in a different way by introducing the "equilibrium" resistance $\left(r_{\mathrm{s}, \mathrm{e}}\right)$, defined as (Pereira et al., 1999, Eq. 16)

$r_{\mathrm{s}, \mathrm{e}}=\frac{\rho c_{\mathrm{p}}}{\gamma} \frac{\Delta+\gamma}{\Delta} \frac{D_{\mathrm{r}}}{A_{0}}$,

which is slightly different from the "climatological" resistance $\left(r_{\text {clim }}\right)$ used by Shuttleworth (2006) $\left(r_{\mathrm{s}, \mathrm{e}}=(1+\right.$ $\Delta / \gamma) r_{\text {clim }}$ ). Taking Eq. (5) into account and expressing $\alpha_{\mathrm{a}}$ as a function of $r_{\mathrm{s}, \mathrm{e}}$ leads to

$$
\begin{aligned}
\alpha_{\mathrm{a}} & =(1+\Delta / \gamma) \frac{f_{\mathrm{c}} r_{\mathrm{a}, \mathrm{c}}-r_{\mathrm{a}, 0, \mathrm{~b}}}{r_{\mathrm{s}, \mathrm{e}}+(1+\Delta / \gamma) r_{\mathrm{a}, 0}} \\
& +\frac{r_{\mathrm{s}, 0}+(1+\Delta / \gamma) r_{\mathrm{a}, 0, \mathrm{~b}}}{r_{\mathrm{s}, 0}+(1+\Delta / \gamma) r_{\mathrm{a}, 0}} .
\end{aligned}
$$

The introduction of the equilibrium resistance $r_{\mathrm{s}, \mathrm{e}}$ into Eq. (12) allows the weather variables linked to radiation balance $\left(A_{0}\right)$ and air moisture $\left(D_{\mathrm{r}}\right.$ and $\left.D_{\mathrm{b}}\right)$ to be encompassed into a unique parameter. Equation (10) constitutes the basic relationship linking crop surface resistance to crop coefficient. It shows that $r_{\mathrm{s}, \mathrm{c}}$ is not a unique function of $K_{\mathrm{c}}$, but also depends on weather data: water vapour pressure 
deficit $\left(D_{\mathrm{r}}\right)$, net radiation $\left(A_{0}\right)$, wind speed through the aerodynamic resistances $\left(r_{\mathrm{a}, 0}, r_{\mathrm{a}, 0, \mathrm{~b}}\right.$, and $\left.r_{\mathrm{a}, \mathrm{c}}\right)$, and air temperature $\left(T_{\mathrm{r}}\right)$ through $\Delta$. It is worthwhile noting that Eq. (10) is only valid under the standard climatic conditions used to derive the value of the crop coefficient. Consequently, the crop surface resistance $r_{\mathrm{s}, \mathrm{c}}$ should first be determined under the "fictitious" standard climatic conditions corresponding to the determination of crop coefficients and then introduced into Eq. (3) with the actual climatic conditions. The problem, however, is to define these fictitious or "preferred" weather conditions in order to estimate the most correct value of crop resistance through Eq. (10).

Shuttleworth (2006) eliminated the dependence of crop surface resistance on some weather variables by equating reference crop evapotranspiration $\mathrm{ET}_{0}$ (Eq. 1) with the Priestley-Taylor estimate (Priestley and Taylor, 1972), expressed as

$\mathrm{ET}_{\mathrm{PT}}=\alpha_{\mathrm{PT}} \frac{\Delta A_{0}}{\Delta+\gamma}$ with $\alpha_{\mathrm{PT}}=1.26$.

This assumption is supported by works on modelling experiments dealing with the daytime evolution of the atmospheric boundary layer (De Bruin, 1983; McNaughton and Spriggs, 1989). It leads to

$r_{\mathrm{s}, \mathrm{e}}=1.26 r_{\mathrm{s}, 0}+0.26\left(1+\frac{\Delta}{\gamma}\right) r_{\mathrm{a}, 0}$.

By putting $\mathrm{ET}_{0}=\mathrm{ET}_{\mathrm{PT}}$, the Matt-Shuttleworth approach makes the equilibrium resistance a simple function of temperature (through $\Delta$ ) and wind speed (through $r_{\mathrm{a}, 0}$ ). In this way, the relationship between crop surface resistance $r_{\mathrm{s}, \mathrm{c}}$ and crop coefficient $K_{\mathrm{c}}$ (Eq. 10) involves only wind speed through the three aerodynamic resistances $\left(r_{\mathrm{a}, 0}, r_{\mathrm{a}, 0, \mathrm{~b}}\right.$, and $\left.r_{\mathrm{a}, \mathrm{c}}\right)$ and air temperature through $\Delta\left(r_{\mathrm{s}, 0}\right.$ being prescribed). The assumption $\left(\mathrm{ET}_{0}=\mathrm{ET}_{\mathrm{PT}}\right)$ is questionable, however, because the effective value of the Priestley-Taylor coefficient depends on the atmospheric conditions and can be fairly different from the preferred value of 1.26. For instance, Jensen et al. (1990) note that $\alpha_{\mathrm{PT}}$ can be as high as 1.74 in arid conditions. This point is thoroughly discussed below using numerical simulations.

\section{Basis of the numerical exploration}

We hereafter examine whether the Matt-Shuttleworth assumption really holds and how the relationship between crop surface resistance and $K_{\mathrm{c}}$ depends on climatic conditions, assessing their impact on the determination of crop surface resistance. For this examination, a different writing of the reference crop evapotranspiration is used. After some algebraic manipulations and introducing the equilibrium resistance $r_{\mathrm{s}, \mathrm{e}}$, defined by Eq. (11), the Penman-Monteith equation applied to the reference crop can be put in a form comparable to Eq. (13) (Pereira et al., 1999, Eq. 18):
$\mathrm{ET}_{0}=\alpha\left(\frac{\Delta A_{0}}{\Delta+\gamma}\right)$ with $\alpha=\frac{1+\frac{\gamma}{\Delta+\gamma} \frac{r_{\mathrm{s}, \mathrm{e}}}{r_{\mathrm{a}, 0}}}{1+\frac{\gamma}{\Delta+\gamma} \frac{r_{\mathrm{s}, 0}}{r_{\mathrm{a}, 0}}}$.

This form of the Penman-Monteith equation allows the exploration of the effective value of the coefficient $\alpha$ compared to the preferred value of 1.26 . It shows that the theoretical form of the Priestley-Taylor coefficient $(\alpha)$ is a complex function of the surface resistance $\left(r_{\mathrm{s}, 0}\right)$ and of some weather variables involved in $r_{\mathrm{s}, \mathrm{e}}$ and $r_{\mathrm{a}, 0}$ (available energy, air humidity, temperature, and wind speed). By setting its value at 1.26, the Matt-Shuttleworth assumption implicitly identifies specific atmospheric conditions, supposed to be those used to determine the crop coefficient.

In FAO-56 (Allen et al., 1998, p. 114), it is specified that the values of crop coefficients "represent those for a subhumid climate with an average daytime minimum relative humidity $\left(\mathrm{RH}_{\mathrm{n}, \mathrm{r}}\right)$ of about $45 \%$ and with calm to moderate wind speeds $\left(u_{\mathrm{r}}\right)$ averaging $2 \mathrm{~m} \mathrm{~s}^{-1}$ ". When $\mathrm{RH}_{\mathrm{n}, \mathrm{r}}$ and $u_{\mathrm{r}}$ differ from $45 \%$ and $2 \mathrm{~m} \mathrm{~s}^{-1}$ respectively, FAO-56 proposes an empirical equation (Allen et al., 1998, Eq. 62) to adjust the $K_{\mathrm{c}}$ value to the prevailing conditions. Nothing is said, however, about air temperature and incoming radiation. In the Matt-Shuttleworth approach, incoming radiation and air humidity are eliminated due to the assumption that $\mathrm{ET}_{0}=\mathrm{ET}_{\mathrm{PT}}$ with $\alpha_{\mathrm{PT}}=1.26$. In Shuttleworth (2006), a typical value of $15^{\circ} \mathrm{C}$ was arbitrarily chosen for reference air temperature $\left(T_{\mathrm{r}}\right)$ with a wind speed of $2 \mathrm{~m} \mathrm{~s}^{-1}$, whereas, in a study on irrigated crops in Australia, Shuttleworth and Wallace (2009) selected a value of $20^{\circ} \mathrm{C}$ for air temperature.

Our simulation process makes use of the semi-empirical formulae given in FAO-56 (Allen et al., 1998) for the different parameters involved in the theoretical relationships described above. The three aerodynamic resistances $\left(r_{\mathrm{a}, 0}, r_{\mathrm{a}, 0, \mathrm{~b}}, a n d r_{\mathrm{a}, \mathrm{c}}\right)$ are calculated without stability corrections following the generic formula

$r_{\mathrm{a}}=\frac{\ln \left(\frac{z-d}{z_{0 \mathrm{~m}}}\right) \ln \left(\frac{z-d}{z_{0 \mathrm{~h}}}\right)}{k^{2} u}$,

where $u$ is the wind speed at a height of $z\left(z_{\mathrm{r}}\right.$ or $\left.z_{\mathrm{b}}\right), d$ the zero plane displacement height, $z_{0 \mathrm{~m}}$ the roughness length for momentum, and $z_{0 \mathrm{~h}}$ the roughness length for scalar (heat and water vapour). Aerodynamic parameters (for the reference crop and the given crop) are calculated as simple functions of crop height: $d=0.67 z_{\mathrm{h}}, z_{0 \mathrm{~m}}=0.123 z_{\mathrm{h}}$, and $z_{0 \mathrm{~h}}=z_{0 \mathrm{~m}} / 10$. The slope of the saturated vapour pressure curve $(\Delta)$ is a function of air temperature (Allen et al., 1998, Eq. 13). The psychrometric constant $(\gamma)$ depends on atmospheric pressure and hence on elevation (Allen et al., 1998, Eqs. 8 and 7). Air density $(\rho)$ is a function of atmospheric pressure and temperature (Allen et al., 1998, Eq. 3.5). Soil heat flux $G_{0}$ is generally neglected on a $24 \mathrm{~h}$ time step, which means that $A_{0} \approx R_{\mathrm{n}, 0}$. The daily net radiation of the reference crop $\left(R_{\mathrm{n}, 0}\right)$ is estimated following Allen et al. (1998, Eqs. 37, 38, 
Table 1. Typical values of daily minimum relative humidity $\left(\mathrm{RH}_{\mathrm{n}, \mathrm{r}}\right)$ and its mean value $\left(\mathrm{RH}_{\mathrm{m}, \mathrm{r}}\right)$ for three types of climate (from FAO56, Table 16).

\begin{tabular}{lrr}
\hline Climatic classification & $\mathrm{RH}_{\mathrm{n}, \mathrm{r}}(\%)$ & $\mathrm{RH}_{\mathrm{m}, \mathrm{r}}(\%)$ \\
\hline Semi-arid (SA) & 30 & 55 \\
Sub-humid (SH) & 45 & 70 \\
Humid (H) & 70 & 85 \\
\hline
\end{tabular}

and 39) from the measured or calculated solar radiation $\left(R_{\mathrm{S}}\right)$ and from the clear sky solar radiation $\left(R_{\mathrm{S}, 0}\right)$, which is approximated by $R_{\mathrm{S}, 0}=\left(0.75+2 \times 10^{-5} z\right) R_{\mathrm{a}}$ (Allen et al., 1998, Eq. 37), $z(\mathrm{~m})$ being the elevation above sea level and $R_{\mathrm{a}}$ the extraterrestrial solar radiation.

\section{Results and discussion}

Numerical explorations are carried out varying primarily air temperature and exploring different conditions of wind speed, air humidity, and radiation. Following FAO-56 (Table 16 and Fig. 32), three types of climate, shown in Table 1, are considered: they are defined as a function of their minimum $\left(\mathrm{RH}_{\mathrm{n}, \mathrm{r}}\right)$ and mean $\left(\mathrm{RH}_{\mathrm{m}, \mathrm{r}}\right)$ relative humidity at the reference height. Solar radiation is taken at sea level and assumed to be at its maximum value $R_{\mathrm{s}, 0}$, corresponding to a clear sky day: $R_{\mathrm{S}}=R_{\mathrm{s}, 0}=0.75 R_{\mathrm{a}}$. In the lower latitudes of both hemispheres (below $4^{\circ}$ ), where irrigation is most needed, the range of value for the extraterrestrial radiation $R_{\mathrm{a}}$ is approximately between 30 and $40 \mathrm{MJ} \mathrm{m}^{-2}$ day $^{-1}$ during the growing season, which corresponds to $R_{\mathrm{s}}$ varying between 22.5 and $30 \mathrm{MJ} \mathrm{m}^{-2} \mathrm{day}^{-1}$. Additionally, and for the sake of convenience, the ratio $f_{\mathrm{c}}=A_{\mathrm{c}} / A_{0}$ is set at 1 in all the simulations.

In Fig. 1, the coefficient $\alpha$, defined by Eq. (15), is plotted as a function of air temperature for different climatic conditions, extraterrestrial solar radiation $\left(R_{\mathrm{a}}\right)$ being set at a constant value of $35 \mathrm{MJ} \mathrm{m}^{-2}$ day $^{-1}$ (i.e. $R_{\mathrm{s}}=R_{\mathrm{s}, 0}=$ $26.25 \mathrm{MJ} \mathrm{m}^{-2} \mathrm{day}^{-1}$ ). The value of $\alpha$ increases with reference temperature, moderately for low wind speed and more significantly for higher wind speed. For the sub-humid climate and a moderate wind speed (which correspond to the conditions under which the crop coefficients were supposedly derived), the value of $\alpha$ is much lower than the preferred value of 1.26 used in the Matt-Shuttleworth approach, whereas, with the semi-arid climate, $\alpha$ is closer to 1.26 (Fig. 1a). Figure 1b shows that, for a wide range of wind speed under a sub-humid climate, the coefficient $\alpha$ is always below the 1.26 value. Therefore, the Matt-Shuttleworth assumption should be considered with much care; using a fixed value for $\alpha$ (1.26) is a way of hiding its complex dependence on weather conditions and can be misleading. As a consequence of this fixed value of $\alpha$, the Matt-Shuttleworth estimate of the equilibrium resistance $r_{\mathrm{s}, \mathrm{e}}$ can be significantly
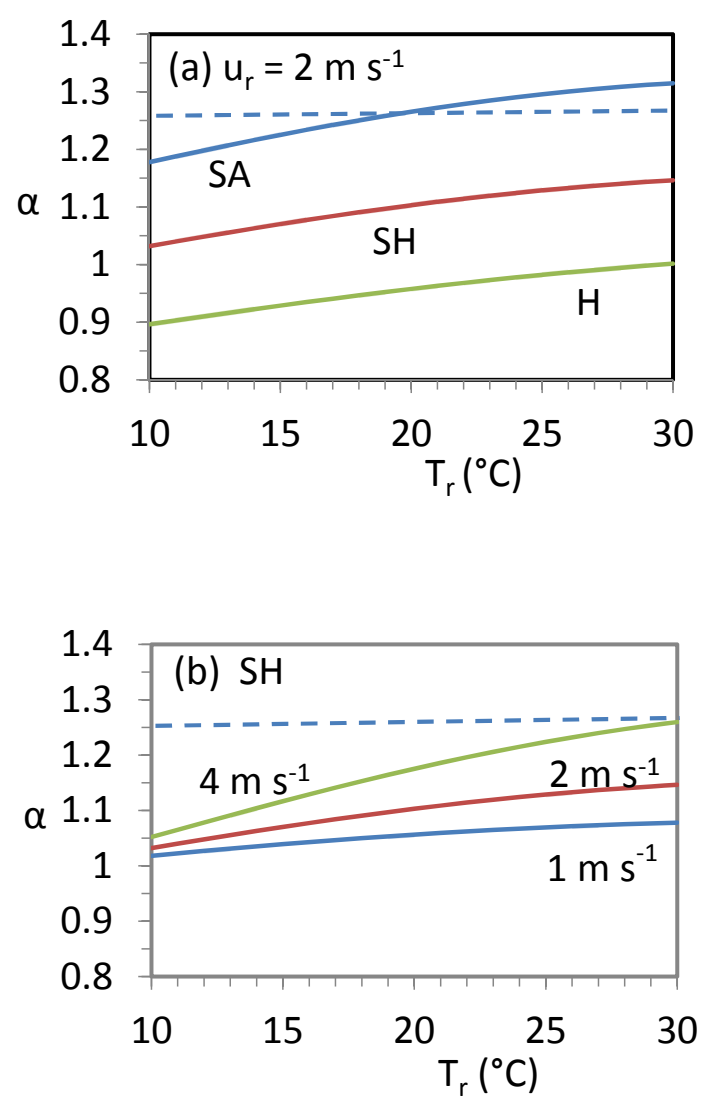

Figure 1. Value of the coefficient $\alpha$ inferred from Eq. (15) as a function of air temperature at reference height, the straight dotted line representing the "preferred" value 1.26: (a) for different climatic conditions (see Table 1) with $u_{\mathrm{r}}=2 \mathrm{~m} \mathrm{~s}^{-1}$; (b) for different values of wind speed under sub-humid conditions ( $\mathrm{SH})$.

greater than the true value for the current range of reference temperature (results not shown).

The influence of weather variables on the relationship between crop surface resistance $r_{\mathrm{s}, \mathrm{c}}$ and $K_{\mathrm{c}}$ is investigated hereafter with and without the Matt-Shuttleworth assumption. Two contrasting cases are considered: one representing the initial stage of an annual crop, with $K_{\mathrm{c}}=0.5$ and a crop height of $z_{\mathrm{h}}=0.5 \mathrm{~m}$, and the other case, with $K_{\mathrm{c}}=1.1$ and $z_{\mathrm{h}}=1.5 \mathrm{~m}$, representing the mid-season stage. The adjustment of crop coefficient to differing climate conditions is systematically applied using the empirical equation given in Allen et al. (1998, Eq. 62). Figure 2 shows how the crop surface resistance varies as a function of reference temperature for two different environmental conditions (semi-arid and sub-humid climates). For the initial stage (Fig. 2a), the surface resistance is high and there is a fairly good agreement between the two estimates (with and without the M$\mathrm{S}$ assumption); in semi-arid conditions, the agreement is almost perfect, and, under sub-humid climates, the $\mathrm{M}-\mathrm{S}$ assumption slightly overestimates the surface resistance by around $30 \mathrm{~s} \mathrm{~m}^{-1}$ (6\% on average). For the mid-season stage 

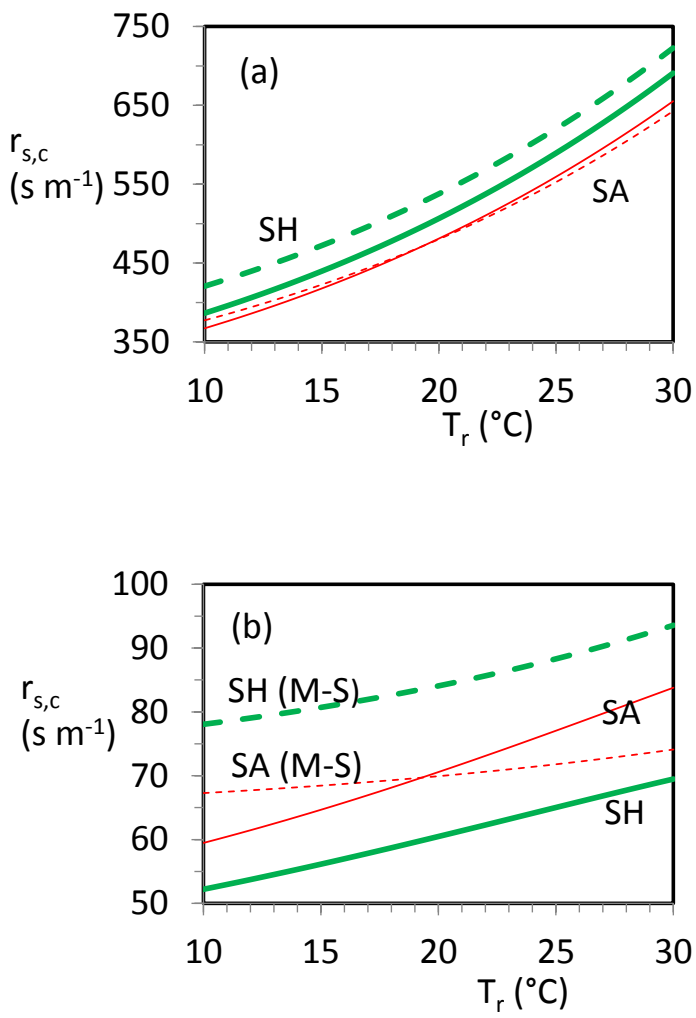

Figure 2. Variation of crop surface resistance as a function of air temperature for two climatic environments - SA: semi-arid (thin line), and SH: sub-humid (bold line), $u_{\mathrm{r}}=2 \mathrm{~m} \mathrm{~s}^{-1}$ - and comparison with the Matt-Shuttleworth estimate (M-S) (dotted line): (a) $K_{\mathrm{c}}=0.5$ and $z_{\mathrm{h}}=0.5 \mathrm{~m}$; (b) $K_{\mathrm{c}}=1.1$ and $z_{\mathrm{h}}=1.5 \mathrm{~m}$.

(Fig. 2b), the surface resistance is lower and the discrepancy is larger in relative value. Under sub-humid conditions, the $\mathrm{M}-\mathrm{S}$ approach overestimates the surface resistance by $40 \%$ on average, whereas, under semi-arid climate, the M-S estimate is much closer to the true value, with a minor overestimation for low temperatures and a slight underestimation for high temperatures.

In Fig. 3a, the surface resistance of a crop with $K_{\mathrm{c}}=1.0$ and $z_{\mathrm{h}}=1.0 \mathrm{~m}$ is plotted against reference temperature for two different values of extraterrestrial solar radiation $\left(R_{\mathrm{a}}\right)$, under sub-humid climate and moderate wind. The M-S approach systematically overestimates the true value of surface resistance, and the higher the solar radiation, the greater the overestimation. Figure $3 b$ shows the net impact of the M-S assumption on the estimate of crop evapotranspiration under standard conditions $\mathrm{ET}_{\mathrm{c}}$ (Eq. 3). The same crop and the same environmental conditions as in Fig. 3a are used. The effect is clearly mitigated since the $\mathrm{M}-\mathrm{S}$ assumption results in a relatively low underestimation: only $-3 \%$ on average for $R_{\mathrm{a}}$ $=30 \mathrm{MJ} \mathrm{m}^{-2} \mathrm{day}^{-1}$ and $-8 \%$ for $R_{\mathrm{a}}=40 \mathrm{MJ} \mathrm{m}^{-2} \mathrm{day}^{-1}$. Given that the surface resistance is only one component of a more complex equation involving other climatic and surface
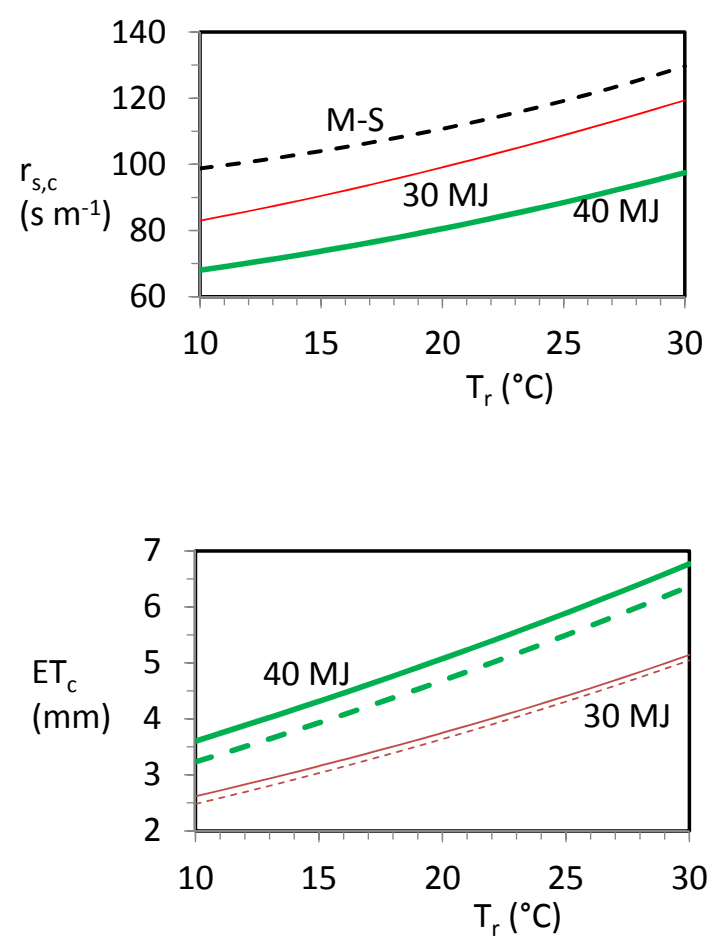

Figure 3. Variation of crop surface resistance $r_{\mathrm{s}, \mathrm{c}}$ (a) and daily standard evapotranspiration $\mathrm{ET}_{\mathrm{c}}(\mathbf{b})$ as a function of air temperature for two different values of extraterrestrial solar radiation $\left(R_{\mathrm{a}}\right)$ expressed in $\mathrm{MJ} \mathrm{m}^{-2}$ day $^{-1}$ (30 and 40) and comparison with the MattShuttleworth estimate (M-S) (dotted line) for a crop with $K_{\mathrm{c}}=1$ and $z_{\mathrm{h}}=1 \mathrm{~m}$, under a sub-humid climate with $u_{\mathrm{r}}=2 \mathrm{~m} \mathrm{~s}^{-1}$.

parameters, the net impact of an overestimated surface resistance is necessarily reduced.

These results show that there is a complex dependence of surface resistance on weather conditions, partially hidden when the Matt-Shuttleworth assumption is used. In the simulations performed above, the $\mathrm{M}-\mathrm{S}$ approach appears to work better in the semi-arid conditions than in the sub-humid conditions described in Table 1. This can be explained by the fact that the coefficient $\alpha$ (Eq. 15) is closer to 1.26 (i.e. $\mathrm{ET}_{0}$ closer to $\mathrm{ET}_{\mathrm{PT}}$ ) in the semi-arid conditions than in the sub-humid conditions, as shown in Fig. 1a. It is indeed well known that the coefficient $\alpha$ can vary from values close to 1 in very humid conditions (high relative humidity, such as in equatorial regions) to values greater than 1.7 in arid conditions (very dry air) (Shuttleworth, 2012, Fig. 23.1). This point has been extensively discussed in the framework of the complementary relationship (Lhomme, 1997). The semi-arid conditions, as defined in terms of relative humidity in Table 1, certainly represents a mid-value of air humidity, where the coefficient $\alpha$ is close to 1.26 and where, consequently, the $\mathrm{M}-\mathrm{S}$ assumption better holds. 


\section{Conclusions}

The relationship between crop surface resistance $\left(r_{\mathrm{s}, \mathrm{c}}\right)$ and FAO crop coefficient $\left(K_{\mathrm{c}}\right)$ is not as straightforward as could be expected because of the interference of weather variables, such as air temperature, solar radiation, wind speed, and air humidity. The Matt-Shuttleworth assumption, which, to some extent, eliminates this interference by equating the reference crop evapotranspiration $\left(\mathrm{ET}_{0}\right)$ to the Priestley-Taylor estimate (ET $\mathrm{ETT}_{\mathrm{PT}}$ with $\alpha_{\mathrm{PT}}=1.26$ ), does not hold in many climatic conditions and can lead to substantial differences between the estimated and true values of surface resistance. We have to recognize, however, that the real impact of the M-S assumption on crop evapotranspiration estimate is relatively minor, given that the generated bias on surface resistance is partially damped when the calculated resistance is introduced into the evaporation formulation.
In order to infer the surface resistance of a given crop from its crop coefficient, it is certainly sounder to work directly with the basic relationship linking crop surface resistance to crop coefficient (i.e. Eqs. 10 and 12) without any assumption, but with the most plausible weather conditions. Indeed, the weather conditions corresponding to a tropical crop (such as cassava, banana, or millet) are surely different from those corresponding to a temperate one (such as winter wheat or potato). Unfortunately, the meteorological conditions corresponding to the tabulated values of FAO crop coefficients are generally not available. Because of that, the transformation of crop coefficients into surface resistances is undoubtedly not an easy task. 


\section{Appendix A}

Table A1. Nomenclature.

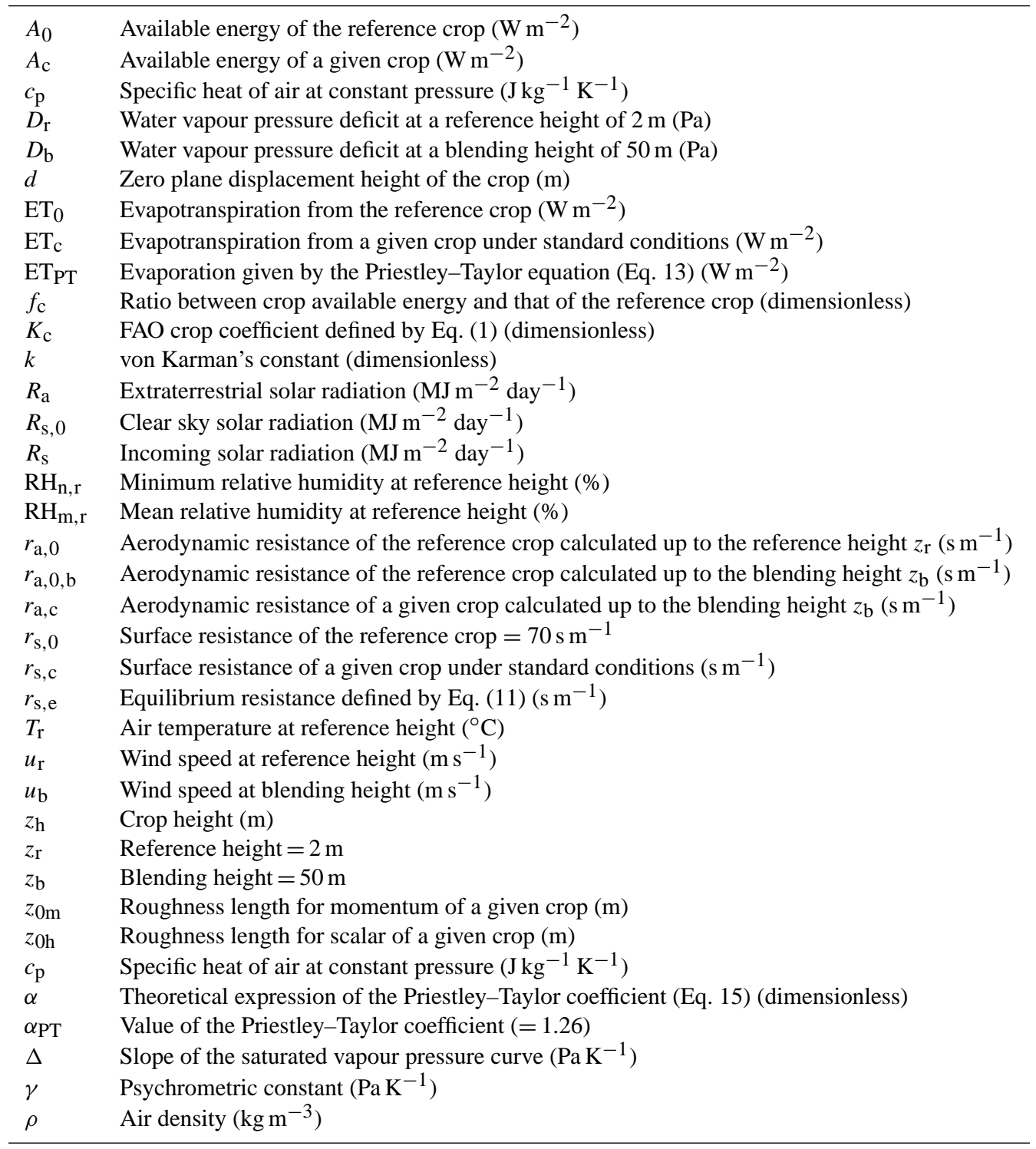


Edited by: F. Tian

\section{References}

Allen, R. G., Pereira, L. S., Raes, D., and Smith, M.: Crop evapotranspiration, Irrig. Drainage Paper No. 56, United Nations FAO, Rome, 1998.

De Bruin, H. A. R.: A model of the Priestley-Taylor parameter $\alpha$, J. Appl. Meteorol., 22, 572-578, 1983.

Doorenbos, J. and Pruitt, W. O.: Crop water requirements, Irrig. Drainage Paper No. 24, United Nations FAO, Rome, 1977.

Jensen, M. E., Burman, R. D., and Allen, R. G.: Evapotranspiration and Irrigation Water Requirements. ASCE Manuals and Reports on Engineering Practices No. 70, ASCE, New York, 1990.

Lhomme, J. P.: An examination of the Priestley-Taylor equation using a convective boundary layer model, Water Resour. Res., 33, 2571-2578, 1997.

McNaughton, K. G., Spriggs, T. W.: An evaluation of the PriestleyTaylor equation, in: Estimation of Areal Evaporation, 89-104, IAHS Publication No. 177, Wallingford, UK, 1989.

Monteith, J. L.: Evaporation and environment, Symp. Soc. Exp. Biol., 19, 205-234, 1965.
Pereira, L. S, Perrier, A., Allen, R. G., and Alves, I.: Evapotranspiration: Concepts and Future Trends, J. Irrig. Drain. Eng., 125, 45-51, 1999.

Priestley, C. H. B., and Taylor, R. J.: On the assessment of surface heat flux and evaporation using large-scale parameters, Mon. Weather Rev., 100, 81-92, 1972.

Shuttleworth, W. J.: Evaporation, in: Handbook of Hydrology, edited by: Maidment, D. R., McGraw-Hill, New York, USA, 4.14.53, 1993.

Shuttleworth, W. J.: Towards one-step estimation of crop water requirements, Trans. ASABE, 49, 925-935, 2006.

Shuttleworth, W. J.: Putting the "vap" into evaporation, Hydrol. Earth Syst. Sci., 11, 210-244, doi:10.5194/hess-11-210-2007, 2007.

Shuttleworth, W. J.: Terrestrial Hydrometeorology, WileyBlackwell, UK, 2012.

Shuttleworth, W. J. and Wallace, J. S.: Calculating the water requirements of irrigated crops in Australia using the Matt-Shuttleworth approach, Trans. ASABE, 52,: 1895-1906, 2009. 